\title{
Information Culture in the Context of Remote Interaction
}

\author{
Natalia Samokhina $^{1 *}$ \\ ${ }^{1}$ "Federal State Budgetary Educational Institution of Higher Education "Nizhnevartovsk State University", Russia \\ "Email: natalia58@yandex.ru
}

\begin{abstract}
The article deals with the peculiarities of information culture transformation in the context of the Covid-19 pandemic. This work also considers concept of information culture and its main aspects, as well as determines the key features of changes in information flows during the pandemic. The author comes to the conclusion that the pandemic has increased the degree of informatization of society without solving the key problems of digital culture, such as the reliability of information, digital security, compliance with ethical and legal norms. The pandemic has led to an increase in the degree of integration of individuals with digital services and platforms, but there has not been a comprehensive increase in information culture, as evidenced, in particular, by the low level of trust in official sources of information. Meanwhile, people are focused on increasing digital integration, which is reflected in the strengthening of ideas about increasing the number of online sales, the spread of remote work and the development of the distance education sector.
\end{abstract}

Keywords: Information culture, Pandemic, Digital security, Digital environment.

\section{INTRODUCTION}

The 2020 pandemic has become a catalyst for the development of modern information culture. The amount of information transmitted in society in a dynamically changing world is increasing every year, and technical means of data transmission are improving. Consumers generally adhere to an intellectual approach - they are well versed in modern trends, can comprehensively evaluate content, and have the skills of independent thinking. Internet communications are of particular importance, as they are based on a dialogic format. The implementation of a self-isolation regime in the first months of the pandemic and other restrictions became possible due to the presence of the necessary level of information culture.

The heterogeneity of various segments of the information society and the media has become more pronounced during the period of coronavirus restrictions. Internet media, through the information resources of traditional media, expand the channels of information collection and can constantly receive the most valuable information in all areas of the world.
Meanwhile, traditional media (primarily television) do not lose their importance and set the main information agenda.

The expansion of digital integration in 2020 has shown both the advantages and disadvantages that characterize the information culture in modern society.

\section{RESEARCH METHODOLOGY}

In the course of the study, an analysis of current scientific sources of Russian and foreign authors was made, as well as data from the Levada Center and the Public Opinion Foundation (POF) were considered. The analysis of opportunities and prospects of remote interaction is made taking into account the general theoretical foundations of the concept of information culture and the experience of remote interaction during the coronavirus pandemic. In the course of the study, the following methods were used: analysis, synthesis, system analysis, dialectical method, method of system analysis, abstraction, system approach, method of studying sources. 


\section{RESEARCH RESULTS}

Information culture has accelerated the pace of development of society and the dynamics of interpersonal interaction, it affects the behavior of people at the psychological level, which leads to the further development of individualization. Due to the wide spread of information technologies, people imperceptibly draw new social norms and behavioral stereotypes, mostly from the online environment. In addition, there is a pluralism of personal ethical ideas, which leads to a blurring of traditional social norms. The web is an open culture, literally a new civilization. It solves the complex problem of cultural exchange, overcoming the territorial and spatial barrier. Zh.N. Pulatov identifies the following aspects of the manifestation of human information culture:

Availability of specific skills in the use of technical means;

$>$ The ability to use modern information technologies in their activities;

Ability to extract information from various sources, present it in an accessible form and use it effectively;

> Mastering the basics of analytical information processing;

Ability to work with different types of information;

Knowledge of the structure and specifics of information flows in your field of activity;

Knowledge of the main regulations in the field of information law;

Knowledge of the basics of ergonomic and information security [1].

The development of information technologies leads to a number of problems. The field of information flows includes objective difficulties in choosing information, serious problems of information security, offenses, and threats to privacy. In the spiritual perception and sociocultural aspect are invaded by foreign culture; there is an increase of culture massification; the phenomenon of cultural eclecticism arises. In the socio-psychological and behavioral aspects there are various information diseases that arise in the information cultural environment, the psychology of consumption prevails, society is corroded by a crisis of trust, there is a risk of individual alienation.

One of the ways to solve the urgent problems is to improve the technological component of information culture. Using the means of information technology, it is possible to obtain the most complete and accurate information with maximum speed and minimum consumption, and ultimately achieve an orderly management of the informatization of society. For example, software manufacturers are making a huge effort to address Internet security and performance issues by offering various products such as firewalls, Internet content filters, etc. J. Piwowarski said that all human societies ever created are information societies. This is due to the fact that without the information flow provided by communication, it is impossible to create and develop a security environment - a fundamental component of any society. J. Piwowarski also points to threats stemming from the loss of control over digital progress, such as those associated with the perception of reality by computer users, parenting through visual media, and poor quality of information on the Internet [2].

At the individual level, information culture manifests itself mainly in cognitive and emotional aspects. E.P. Nikolaeva points out that a high level of personal information culture leads to the development of the following qualities:

Information literacy, which contributes to the logical construction of a strategy for finding information on Internet resources;

Motivation on the needs, the expansion of horizons and the development of computer skills;

Formation of a special type of thinking, the main components of which are independence, creativity and critical thinking [3].

Modern information culture is based primarily on remote interaction, which involves not only the consumption of content, but also the implementation of social communication using technical means.

The 2020 pandemic found the world in a developed information culture, in which people are used to remote interaction. Restrictions related to the coronavirus were made taking into account the infrastructure capabilities and the degree of informatization of society. In these conditions, it was necessary to actively notify citizens about the current state of affairs. The possession of timely information on a particular topic by the majority of the population is covered by the concept of coawareness. The eclectic nature of information flows leads to fragmented knowledge, so it is necessary that information is broadcast on a large number of different information channels - television, radio broadcasting, printed publications, alerts in crowded places, SMS alerts. O.G. Shchenina writes that co-awareness was formed under the influence of the media, which broadcast the decisions of the authorities depending on the current situation with the spread of coronavirus. Its manifestation is reflected in the actions and behavior of people:

Self-isolation as the main sign of co-awareness;

The requirement of respect for social distance; 
Mandatory use of medical masks and gloves in public places;

\section{Digital passes [4].}

The phenomenon of co-awareness implies access to at least one channel of timely information, which requires a person to possess a minimum set of skills in the field of information culture. However, full-fledged remote interaction requires the use of various technical means, services and digital platforms.

The most significant from the point of view of remote interaction is the practice of educational activities. Distance education is possible in the following two forms:

Synchronous training (students have classes at the same time with the participation of a teacher);

Asynchronous learning (each student learns the material at a convenient time independently and individually).

Fully distributed asynchronous learning distance learning is a real form of distance learning that allows you to learn at different times and in different places according to the progress of each person, i.e. as needed. People can view and download various educational resources (such as multimedia software, digital audio, digital video, and various data) on the Internet through a computer according to their needs.

In the first period of the pandemic, general education schools switched to distance learning, which in the mass version had never been practiced before. In the context of distance learning in secondary schools, such platforms as "Google Class", "Russian electronic school", "Uchi.ru", "Dnevnik.ru", "Education. Yandex", "YAclass" and many others became popular. These platforms present whole courses for each subject with the presence of topics on the school curriculum with video accompaniment [5]. Students mastered the educational program in the remote format by independently reading educational literature, watching training videos, and doing homework. There were controversial situations from the point of view of ethics and legislation. So, for example, there was a practice of recording on video the process of performing a set of physical education exercises on the instructions of the teacher, which can be interpreted as an intervention in private life.

University education is in a compromise zone - we are talking about the so-called "hybrid" mode of training, when theoretical classes are conducted remotely, practical classes are held in the traditional mode. In addition to the problems with the control of academic performance, the mixed mode of education has had a negative impact on student culture.
The problem of distance education is related to the consumption of various information products focused on the implementation of non-formal educational tasks. O.V. Savel'eva, Yu. M. Lyakhovskaya writes that almost any online course purchased on the Internet was prescribed by a professional coach or athlete. Of course, scammers have already begun to appear in this area, but it is the popularity of people who provide such services that can play a good service in identifying fraud. The coach also prepares a course of exercises in advance, which is not only performed simultaneously with the trainee, but also monitors the performance in real time, not allowing you to make mistakes and get injured [6]. We believe that randomly distributed information products that do not require confirmed qualifications from their authors do not always have the necessary quality. Moreover, sales depend primarily on the effectiveness of the distribution model and the charisma of the author. The problem can be solved at the individual level by improving personal information culture and comprehensive analysis of sources.

The saturation of remote interaction practices has led to an increase in the relevance of not only educational, but also other services. One of the priorities of modern information development is the formation of the practice of telemedicine, when a personal visit to the doctor can be replaced by remote interaction. At the present time, only the practice of psychology and psychotherapy is being developed. E.V. Kosilova notes that distance psychotherapy with the help of various Internet tools is developing and should continue to develop. Its main advantage is not cheapness and accessibility, as many believe, but ease of communication for the patient. Also, attention should be paid to communication using text messengers, since it is even more facilitated due to its "disembodied" nature and thus is suitable for patients with reduced social adaptation [7].

During the pandemic, people began to spend more time on social networks. T. Nabity-Grover, C. Cheung, J. Thatcherc points out that during the first months of the pandemic, the use of social media platforms increased by $61 \%$, as people use the platforms to stay connected with family, friends and colleagues. Facebook and Instagram grew by more than $40 \%$ worldwide from February to March 2020; messaging on Facebook Messenger, WhatsApp and Instagram increased by $70 \%$ during this period, and live stream views doubled [8]. The increase in remote interaction in social networks is primarily due to the appearance of additional free time, as well as the need to solve educational and labor problems.

Of course, the pandemic contributes to online shopping. R.Y. Kim, using the example of the United States, points out that a significant part of those who started shopping online late moved to electronic markets after Covid-19. Among the respondents, $11 \%$ of 
generation $\mathrm{Z}, 10 \%$ of Millennials and $12 \%$ of Generation X, as well as $5 \%$ of baby-boomers, bought something online for the first time because of the pandemic [9]. It should be noted that e-commerce gradually gained momentum by 2020 . In the Russian market, such platforms as "Ozon" and "AliExpress" are very popular. "Ozon" is the leading multi-category ecommerce platform in Russia. Ozon's gross merchandise value (GMV) increased by $152 \%$ in the first half of 2020. "Ozon" is one of the most famous online stores in Russia. Unlike "AliExpress" and "Amazon", the store operates mainly in the Russian market. Sales dynamics show that the pandemic has had a positive impact on electronic sales, which is highly expected.

Special attention should be paid to the social attitudes associated with information culture during the pandemic. Serbian researchers, A. Jovančević, N. Miličević conducted a sociological analysis of information culture in the context of the Covid-19 pandemic among Serbs and Latin Americans. The results show that a high level of optimism indicates a high level of respect for the measures taken against the spread of Covid-19. Optimism was positively associated with the internal locus of control. The correlation between the source of information and trust in this source ranged from medium to high (Serbs: $r=0.60$ to $r$ $=0.72$; Latinos: $r=0.47$ to $r=0.73 ; p<0.05)$. These results show that higher trust in a source correlates with a higher probability of collecting information from that source. Notably, a negative correlation was found between trust and belief in conspiracy theories [10]. Here, the dynamics of attitudes towards official sources of information are highlighted, while the opposite pole is different conspiracy theories. In Russia, the level of trust is low, one of the consequences of which is partial non-compliance with the restrictions established to reduce the rate of spread of coronavirus. In April-July 2020, the Levada Center conducted a study of the operating mode during the pandemic. As a result of the study, it was determined that during the months of selfisolation, some of the respondents switched to remote work mode, while some of the respondents were on forced leave without saving or with partial saving. It is noteworthy that the transfer to a reduced working day or week was not distributed. At the same time, the level of confidence in information about the pandemic from official sources decreased $-22 \%$ of respondents trusted official information to a significant extent in April, but in July this value decreased to $15 \%$. The growth of partial trust (from $35 \%$ to $39 \%$ ) and the growth of complete distrust (from $24 \%$ to $27 \%$ ) increased [11].

We believe that after the victory over the pandemic, the information culture will not return to its previous state - the habits of remote interaction will remain. According to a study by the Public Opinion Foundation (POF), most citizens do not believe that there will be drastic changes after the pandemic, but some habits will go into "peacetime". Thus, 33\% of respondents believe that distance education will spread more widely in the country, $31 \%$ - that people will buy more via the Internet, $28 \%$ - that there will be more "remote workers", the same number - that courier delivery will spread more widely [12].

\section{CONCLUSIONS}

Information culture in 2020 has undergone a number of certain changes, which are both quantitative and qualitative in nature. The degree of remote interaction has significantly increased, which has resulted in increased activity in social networks, the development of the e-commerce sector, and increased interest in information products. At the same time, within the framework of remote interaction, it was necessary to solve a number of previously unusual tasks directly related to labor and educational activities.

Social expectations in Russia within the framework of information culture are characterized by a low level of trust in official sources, as well as a focus on further remote interaction in the foreseeable future.

Increasing the dynamism of information processes is associated with the unsolved problems associated primarily with the security of networks and communications, the confidentiality of personal data of users. In addition, the issue of the quality of information products and control over remote work and distance learning has become more acute.

Thus, information culture develops along the path of acquiring skills in using remote technologies, which corresponds to the technological component of information culture.

\section{REFERENCES}

[1] Zh.N. Pulatov, Information Culture, Actual Problems of Humanities and Natural Sciences 11-2 (2017) 67-69 (In Russ.).

[2] J. Piwowarski, Information Society and the Protective Influence of Security Culture, A Shift in the Security Paradigm, 2020, pp. 209-234. DOI: https://doi.org/10.1007/978-3-030-43253-9_13J.P

[3] E.P. Nikolaeva, Information Culture of the Individual, Bulletin of Science and Education 14(92) (2020) 59-62 (In Russ.).

[4] O.G. Shchenina, Co-awareness in Russian Society During the Covid-19 Pandemic, Bulletin of the Moscow State Regional University 3 (2020) 108119 (In Russ.).

[5] M.A. Sapunova, The Effectiveness of Distance Learning in School During the Pandemic, 
Achievements of Science and Education 12(66) (2020) 77-78 (In Russ.).

[6] O.V. Savel'eva, Yu.M. Lyakhovskaya, Sports Sphere in the Context of the Coronavirus Pandemic: the Most Successful Solutions of the Remote System of Sports. SKIF, Questions of Student Science 5(45) (2020) 301-307 (In Russ.).

[7] E.V. Kosilova, Philosophical Foundations of Distance Psychotherapy in the Era of Computer Culture, Psychology and Psychotechnics 3 (2018) 172-176. DOI: https://doi.org/10.7256/24540722.2018.3.27049 (In Russ.).

[8] T. Nabity-Grover, C. Cheung, J. Thatcherc, Inside Out and Outside In: How the COVID-19 Pandemic Affects Self-Disclosure on Social Media, International Journal of Information Management $55 \quad$ (2020) 1-5. DOI: https://doi.org/10.1016/j.ijinfomgt.2020.102188

[9] R.Y. Kim, The Impact of COVID-19 on Consumers: Preparing for Digital Sales, IEEE Engineering Management Review, No. 3, pp. 212218.

DOI: https://doi.org/10.1109/EMR.2020.2990115

[10] A. Jovančević, N. Milićević, Optimism-Pessimism, Conspiracy Theories and General Trust as Factors Contributing to COVID-19 Related Behavior - A Cross-Cultural Study, Personality and Individual Differences, Iss. 167, pp. 1-12. DOI: https://doi.org/10.1016/j.paid.2020.110216

[11] Coronavirus: Fear and Employment, Levada Center. Retrieved from: https://www.levada.ru/2020/07/31/koronavirusstrah-i-zanyatost/ (In Russ.)

[12] The World After the Pandemic, Public Opinion Foundation. Retrieved from: https://fom.ru/Obrazzhizni/14386 (In Russ.). 